\title{
Triacylglycerol Metabolization during Germination of Sea Buckthorn Seeds
}

\author{
Vasily Pchelkin, Vladimir Tsydendambaev and Andrei Vereshchagin*
}

Timiryazev Institute of Plant Physiology, Russian Academy of Sciences, Botanicheskaya ul. 35, 127276 Moscow, Russia

\begin{abstract}
Dark germination of sea buckthorn seeds was characterized by an initial 3-day-long lag-period, when the contents of triacylglycerols (TAGs) and total acyl-containing lipids (ACLs) remained nearly the same due to retardation in the lipid metabolization. Subsequently, TAG content decreased rapidly, and by the 10th day of germination, it did not exceed $5 \%$ of total lipids. In this process, total saturated (S) and total unsaturated fatty acids (U), as well as various TAG types such as $\mathrm{S}_{2} \mathrm{U}, \mathrm{SU}_{2}$, and $\mathrm{U}_{3}$, were consumed at nearly similar relative rates. At the same time, separate TAG groups, which included one of the individual fatty acids, such as palmitic (P), stearic (St), oleic (O), linoleic (L), or linolenic (Le), differed from each other in the intensity of degradation. For L- and Le-TAGs, initial and final concentrations were similar, while initial concentrations of St- and O-TAGs by the 10th day of germination increased 2.3- and 1.5-fold, respectively, and as regards P-TAGs, this value decreased 3.5-fold. Thus, P-TAGs considerably exceeded other TAG groups in their consumption rate in seedlings, while St- and O-TAGs ranked below them in this respect.
\end{abstract}

\section{INTRODUCTION}

Sea buckthorn belongs to a group of higher plants (e.g. oil palm, avocado, olive, etc.), which contain a considerable portion of their fruit oil not only in the seeds of a fruit, but also in its mesocarp and therefore are designated as the plants with an oil-bearing mesocarp (POM) [1].

In our earlier studies devoted to the mature fruit oils of several sea buckthorn genotypes, we have established the contents and quantitative composition of fatty acids (FAs) and triacylglycerols (TAGs) in the oils of both mesocarp [2$5]$ and seeds [6, 7], as well as the changes in these parameters during fruit maturation $[1,3,4,7]$. It was found that the seed oils dramatically differed from the mesocarp ones as regards the concentration, accumulation pattern, FA and TAG compositions, as well as the effects of genotype factors on these compositions [5, 8].

It is well known, that, in POM fruits, mesocarp oil cannot be used by seedlings for "making" a new organism, and so their seed oil serves here as the only source of carbon and energy during germination before the onset of photosynthesis in this organism. However, the pattern of oil TAG consumption in the course of germination has not been studied in any POM species up to now, and therefore it was of interest to perform such study using sea buckthorn seeds, which contain about $10 \%$ oil in the cotyledons [1].

At the same time, there are many oleiferous and nonoleiferous plant species other than POM, in which the dynamics of dry weight, oil content, and TAG degradation in seedlings has been investigated, but the evidence obtained remains in many cases a rather contradictory one. Thus, some authors asserted that seed germination was accompanied by a

*Address correspondence to this author at the Timiryazev Institute of Plant Physiology, Russian Academy of Sciences, Botanicheskaya ul. 35, 127276 Moscow, Russia; Tel: 7 (499) 231 8351; Fax: 7 (495) 977 8018;

E-mail: lipids@ippras.ru rapid decrease in the dry matter [9] and TAG [10] contents, while other ones claimed that such decrease was slow [11, 12]. Furthermore, according to some evidence, these changes were preceded by a several-day-long lag-period [10, 11], whereas no such evidence was found elsewhere [12, 13].

As regards the selectivity of catabolism of definite FA and TAG types and molecular species during germination, one must stress, first of all, that, at present, there is no respective information concerning TAG types and very few data on FA types $[14,15]$. In many cases, the FA species composition of TAGs and the molecular species composition of the TAGs themselves remained unchanged [10, 11, 13, 16], while in other ones, the concentration of a given individual FA in total TAGs either increased, or decreased depending on a plant species under investigation [15, 17-19]. Moreover, the patterns of germination-induced quantitative dynamics of TAG molecular species were shown to be in conflict to each other $[20,21]$.

Taking into account such situation, the objectives of our work were to obtain some initial evidence on oil metabolism in the seedlings of a POM species as well as to contribute to resolving the contradictions regarding the dynamics of dry mater and oil mobilization during seed germination in general. The results of our investigation are outlined in the present communication.

\section{MATERIALS AND METHODS}

Sea buckthorn (Hippophae rhamnoides L., cv. Katunskaya-24) mature fruits were collected in a local botanical garden; the seeds were separated and stored at a chilling temperature. The seeds were germinated in darkness at $25^{\circ} \mathrm{C}$ on moist filter paper, and their germinability was close to $100 \%$. Intact seeds ( $0^{\text {th }}$ day) and their 1-, 2-, 3-, 4-, 5-, 6-, 8-, and 10-day-old seedlings were used in the experiments. Each time point comprised 60 seeds or their seedlings; 20 of them were used for determining the changes in the cotyledon fresh and dry weights, and the cotyledon material from 40 seeds 
was fixed with boiling isopropanol and homogenized. At the $10^{\text {th }}$ day, the seedling development was at the stage of the first true leaf emergence; their oil reserves were nearly exhausted, and so the experiment was terminated.

Total lipids from the homogenate were extracted as described earlier [6]. Absolute contents and composition of FAs in the total acyl-containing lipids (ACLs) of the extract and in the TAGs isolated from the extract by preparative adsorption chromatography [6] were established by GLC of FA methyl esters in the presence of an internal standard [8] using the Tracor 540 Gas Chromatograph apparatus (Tracor, USA) equipped with a 50-m-long capillary column having an internal diameter of $0.25 \mathrm{~mm}$ and containing a grafted cyanopropyl methyl silicone polar liquid phase (CPS-1; Quadrex, Japan). The chromatograms were run under following conditions: inlet argon pressure, $140 \mathrm{kPa}$; carrier-gasflow linear velocity in the column, $15 \mathrm{~cm} / \mathrm{s}$; sample size, 10 $\mu \mathrm{g}$; flow split ratio, 1:100; starting column temperature, $80^{\circ} \mathrm{C}$; temperature program, from $80^{\circ} \mathrm{C}$ at a rate of $30^{\circ} / \mathrm{min}$ to $140^{\circ} \mathrm{C}$, and from $140^{\circ} \mathrm{C}$ at a rate of $10^{\circ} \mathrm{C} / \mathrm{min}$ to $170^{\circ} \mathrm{C}$; finally, the temperature was raised at $4^{\circ} \mathrm{C} / \mathrm{min}$ to $220^{\circ} \mathrm{C}$.

Positional-species composition (PSC) and positional-type composition (PTC) of TAGs were calculated from their FA composition [6] using the Ekokhrom computer program complex software [5].

The means of five replications each containing 20 and 40 seeds (see above) and their standard errors were determined at $P=0.05$.

\section{RESULTS AND DISCUSSION}

In the course of two-day-long imbibition, the seeds acquired softer coats, and the radicle emerged from the coat. This was followed by an intense growth of seedling axial organs. The cotyledon fresh weight content steadily increased, and by the 10th day exceeded 5-fold the initial one (Fig. 1).

Earlier, similar results were obtained in the experiments with cotton, hazel, and yellow foxtail seeds, in which this value increased 3-8-fold during germination [16, 22, 23]. At the same time, a dry weight decrease, caused by reserve consumption during the sea buckthorn seedling growth, proceeded steadily, but at a slow rate. A slow mobilization of cotyledon reserves was also observed in the experiments with linseed [12], hazel [16], tobacco [24], yellow foxtail [23], and two cruciferous species [11]; however, in corn [25], cotton [22], nut pine [9], and water melon [26] seeds, their dry weight contents decreased two- or even threefold by the end of germination. The causes for differences between various plant species in this respect are still unknown at present.

As shown in Fig. (2), the absolute TAG and ACL contents in the seedling cotyledons remained nearly constant during the first three days-long imbibition. Growth induction following three days after the onset of germination was accompanied by a rapid decrease in the cotyledon total TAG level, but at the 8th day, i.e. after the dark seedling growth slowed down (Fig. 1), TAG content did not change any longer. Thus, intense shifts in the TAG level took place only during the period of active growth. Cotyledon ACLs included, along with TAGs, also polar lipids, and their predomination at the later stages of germination reflected an intense formation of cotyledon membrane lipids accompanying the TAG breakdown.

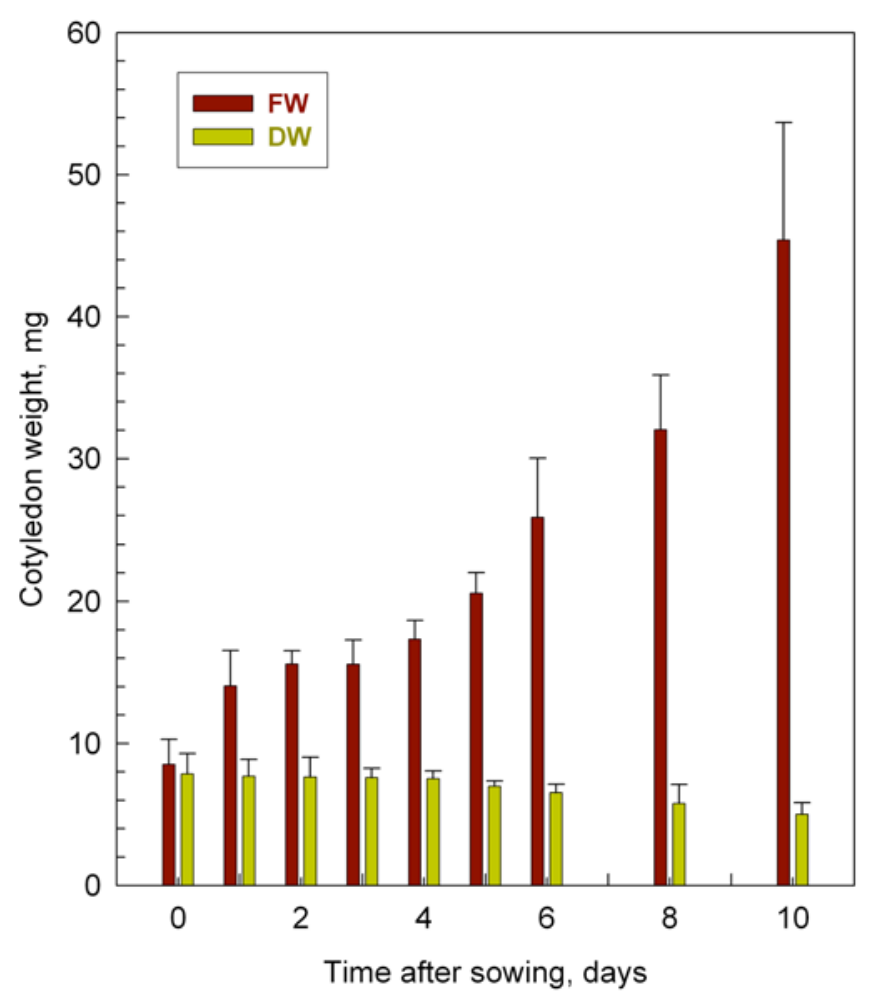

Fig. (1). Developmental changes in the fresh and dry weights (FW and DW) of sea buckthorn seedling cotyledons. The means of five replications each containing 20 seeds and their standard errors determined at $P=0.05$ are shown.

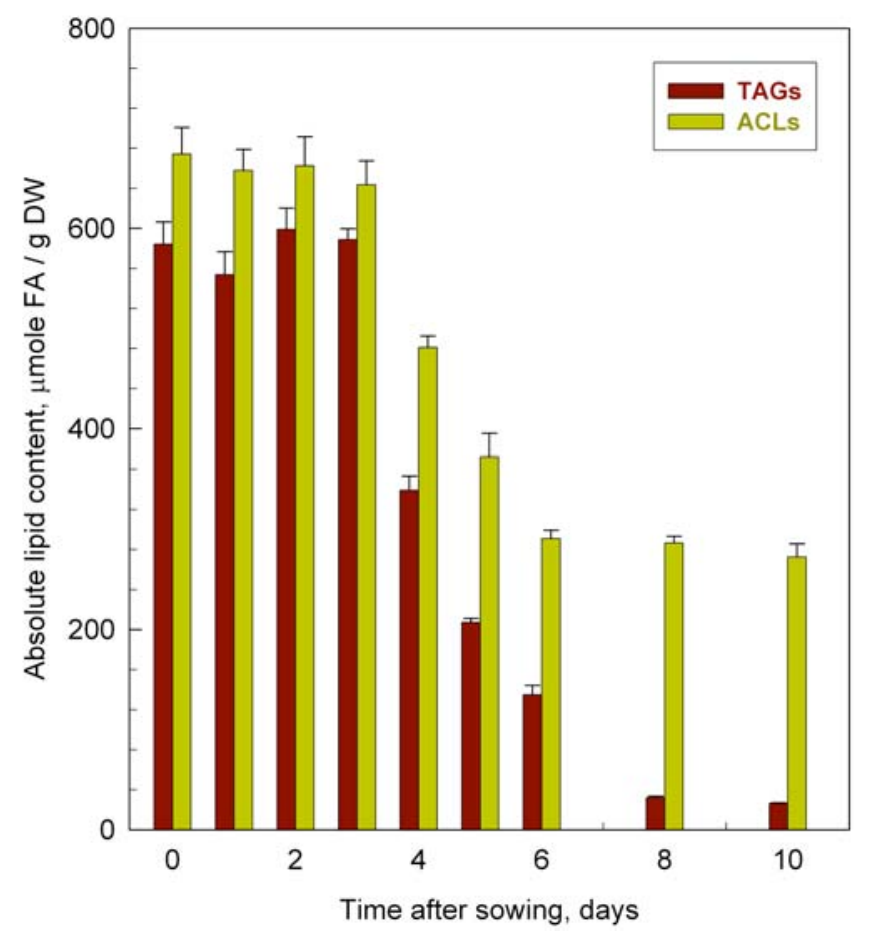

Fig. (2). Developmental changes in the TAG and ACL absolute content of sea buckthorn seedling cotyledons. The means of five replications each containing 40 seeds and their standard errors determined at $P=0.05$ are shown. 
Previously, it was shown that dry matter mobilization in the seedlings proceeds at the expense of the reserve oil utilization. This utilization sequentially includes acid lipase hydrolysis of TAGs on the oleosome surface; glyoxysomal decomposition of the FAs thus formed in the course of FA $\beta$ oxidation and glyoxysomal cycle reactions; and finally, gluconeogenesis yielding sucrose as a source of carbon and energy for the growing vegetative tissues [9, 27-29].

As a result of germination, the absolute TAG content in sea buckthorn cotyledons decreased almost 40 -fold, and by the 10th day it did not exceed 5\% of total ACLs (Fig. 2). Oil consumption as intense as this was never observed in higher plant seedlings. For instance, only during the germination of borage [10], sunflower [20], euphorbia [30], alfalfa [27], castor [28], and rape [31] seeds, their oil contents could decrease 20-, 19-, 17-, 13-, 13-, and 10-fold, respectively, whereas no more than 1.1 - 9-fold decrease in these contents was noticed in other available reports referred to in the References below.

Above, it was shown that the absolute TAG content in sea buckthorn cotyledons remained almost constant during the initial three days of germination (Fig. 2). The occurrence of an initial lag-period in the process of TAG mobilization in germinating seeds was also found in many other plant species. At present, it is suggested that this phenomenon can be brought about by a number of causes. On the one hand, they involve delays in the biosynthesis or activation of the enzymes of this process, primarily lipase; in the transport of these enzymes into oleosomes; or in the formation of organelles, such as glyoxysomes, mitochondria, etc., which are essential for TAG and FA degradation. On the other hand, they involve a temporary inhibition of FA breakdown under the action of excess soluble carbohydrates in the cotyledon tissues $[14,23,32]$.

It is of interest that, along with sea buckthorn, a lagperiod of TAG utilization was observed up to now almost exclusively in the seedlings of non-oleiferous plant species, such as maize [25], euphorbia [30], borage [10], manihot [33], nut pine [9], hazel [28], tobacco [24], yellow foxtail [23], etc. At the same time, this phase was absent in many major industrial oil crops, such as sunflower [34], soybean [13, 17], linseed [12], rapeseed [18, 31], castor bean [28], and cotton [35]. In our opinion, it cannot be excluded that these differences may be caused by different oil content in the seeds of these groups of plants. In the latter group, an efficient germination of oil-rich seeds is critically dependent on a rapid mobilization of reserve TAGs, and therefore, an immediate activation of all biochemical and physiological mechanisms of TAG metabolization referred to above is of vital importance for the seedling survival. At the same time, in the seeds with lower oil content, the onset of germination can be provided at the expense of other reserves, e. g. carbohydrates, and so TAGs mobilization may be started after a certain lag-period.

The investigation of possible changes in the seedling TAG composition was started from determining the dynamics of absolute contents of separate types of their FAs, both saturated (S) and unsaturated (U) ones; here and below, $\mathrm{S}$ is the sum of stearic (St) and palmitic (P) acids, and $\mathrm{U}$, the sum of oleic (O), linoleic (L), and linolenic (Le) acids. During germination, the levels of $\mathrm{S}$ and $\mathrm{U}$ could differ by $1-1.5$ orders of magnitude and more, and therefore these values were plotted on a logarithmic scale. As shown in Fig. (3), UFAs considerably exceeded the S-FAs in their contents in TAGs. At the same time, the respective dynamics patterns were similar to each other in their shape. Thus, the TAGs, which included S- or U-FAs, were consumed in seedlings at about the same rate.

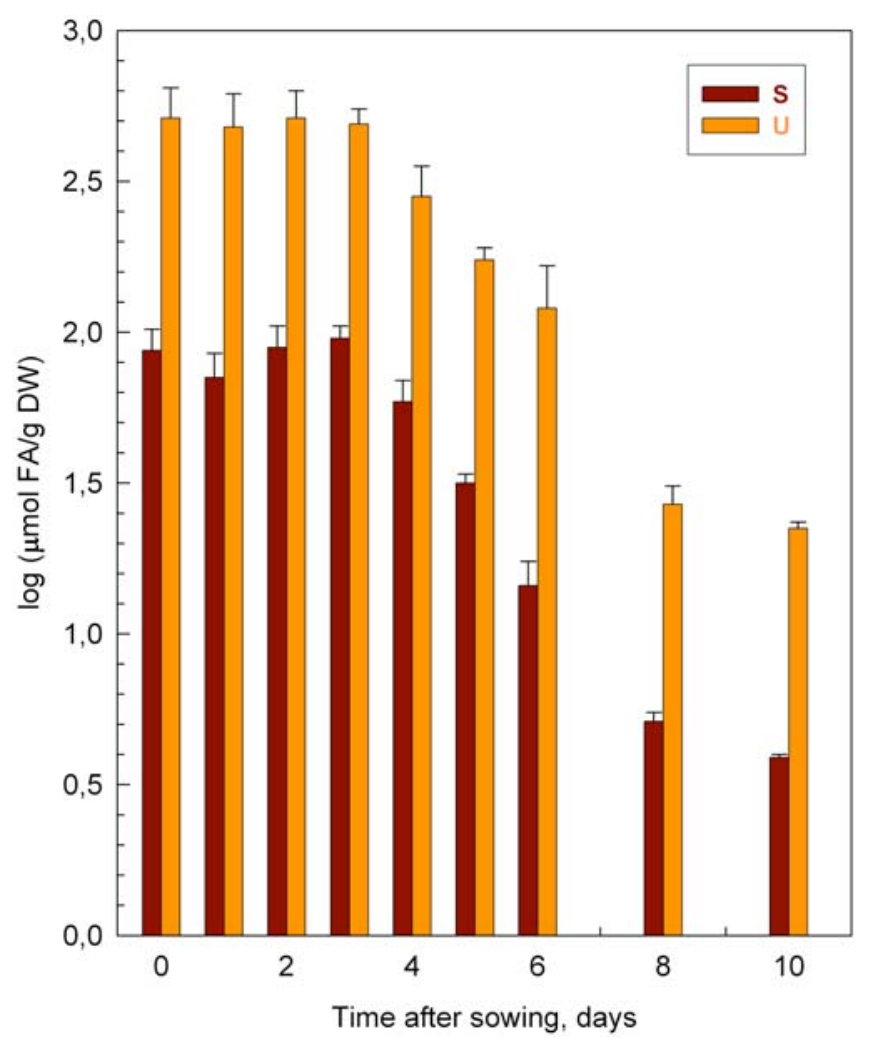

Fig. (3). Developmental changes in the absolute content of separate FA types ( $\mathrm{S}$ and $\mathrm{U}$ ) of TAGs of sea buckthorn seedling cotyledons. See also Fig. 2.

The dynamics of the quantitative FA composition of TAGs can be regarded as an important metabolic index of this process. As shown above, S-FAs and U-FAs were degraded at about the same rate, and therefore in sea buckthorn seeds, their quantitative ratio remained constant (Fig. 3). At the same time, the germination of berseem seeds, which are similar to sea buckthorn seeds in their FA composition, was accompanied by a 1.5 - 2-fold decrease in $\mathrm{S}$ concentration and a corresponding increase in $U$ concentration in TAGs [14], while in fenugreek seeds, the pattern of these changes was quite opposite [15].

It was also of interest to determine the dynamics of TAG PTC of seedlings as a most general parameter of TAG composition [6]. It could be suggested that, at definite stages of germination, various TAG types could be consumed at different rates. However, it was found (Fig. 4) that, in spite of certain fluctuations in the contents of separate TAG positional types, their initial and final levels were almost the same. Therefore, as a whole, TAG degradation during germination did not involve TAG PTC; in other words, there was no selective consumption of certain TAG types. 
In order to study the dynamics of TAG composition in developing cotyledon leaves in more detail, we have determined changes in the absolute contents of individual FA species included in TAGs. These results, like the $\mathrm{S}$ and $\mathrm{U}$ values (Fig. 3, see above), were also plotted on a logarithmic scale. As shown in Fig. 5B, the developmental changes for $\mathrm{L}$ and Le acids were, as a whole, similar in their shape, while the pattern for $\mathrm{O}$ acid content appreciably departed from them in this respect. At the same time, respective patterns for St and $\mathrm{P}$ acids (Fig. 5A) considerably differed from each other, from the patterns in Fig. 5B, and from the monotone pattern for $\mathrm{S}=\mathrm{St}+\mathrm{P}$ in Fig. (3).

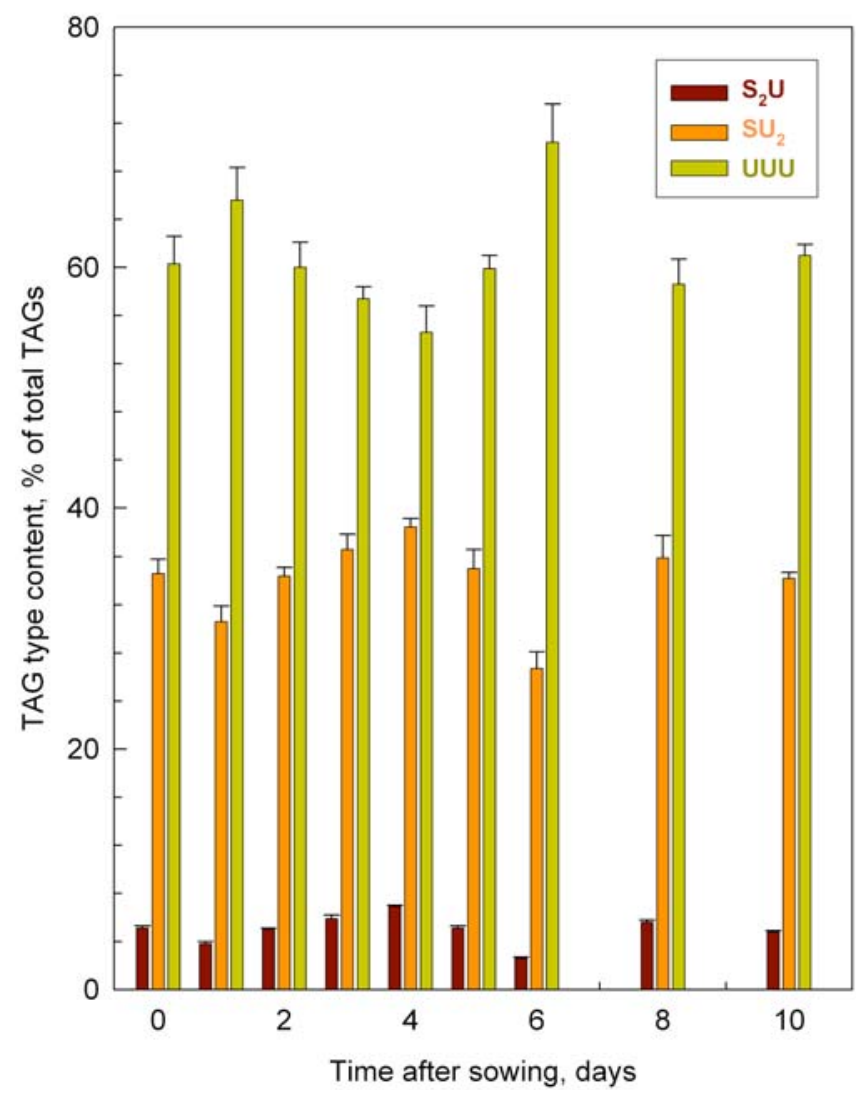

Fig. (4). Developmental changes in the TAG PTC of sea buckthorn seedling cotyledons. SSS-TAGs were absent in the cotyledons. See also Fig. 2.

After finding these differences, we considered it necessary to determine the effect of germination on TAG PSC. Meanwhile, it turned out that the number of TAG individual species present in the total TAGs of seeds to the extent of $0.1 \%$ or more amounted to $70-80$, and therefore, it would not be worthwhile to present here the dynamics' data for each of them. Thus, Fig. (6) displays the germinationinduced changes in the relative contents of only five groups of TAG positional species. These groups consisted of those TAGs, which included one of the five FAs, viz., L, Le, O, St, or P.

It can be seen that L-TAGs and Le-TAGs were similar in their initial and final levels. At the same time, by the end of germination, the initial concentrations of St-TAGs and OTAGs increased 2.3- and 1.5-fold, respectively, whereas for P-TAGs, this value decreased as much as 3.5-fold. Therefore, among the changes in the composition of sea buckthorn seed TAGs, one must first of all consider a decrease in their $P$ concentration (Fig. 5A). Possibly, it was related to certain shifts in the activity of such enzymes of P biosynthesis as 3ketoacyl-ACP-synthetase and palmitoyl-ACP thioesterase [20]. An increase in the amount of St, a certain rise in the $\mathrm{O}$ level, and no changes in the contents of $\mathrm{L}$ and Le were also observed.

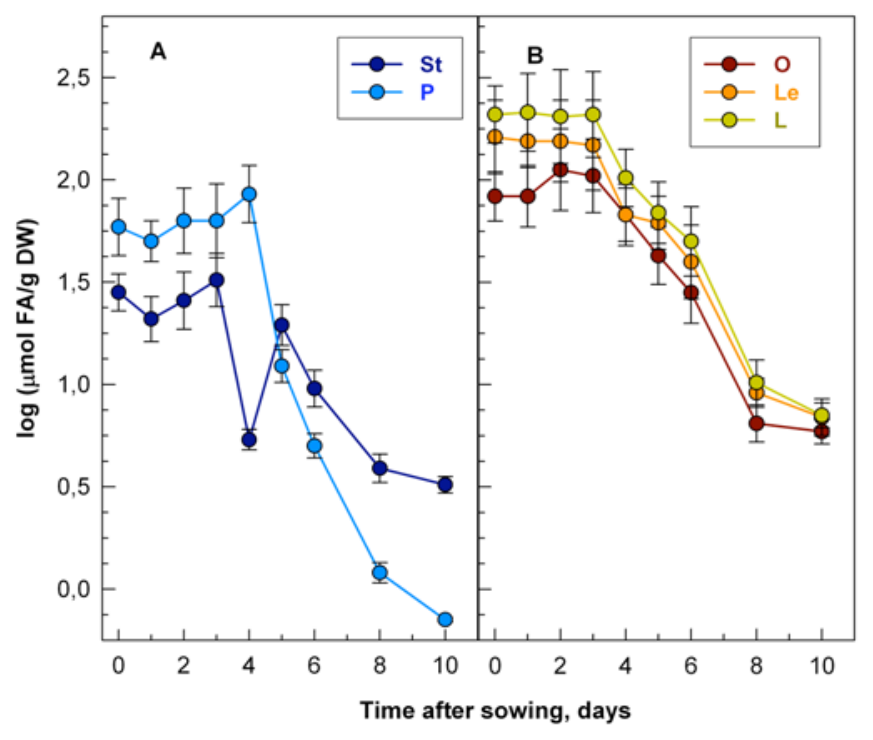

Fig. (5). Developmental changes in the absolute content of separate FA species of TAGs of sea buckthorn seedling cotyledons. A: SFAs; B: U-FAs. See also Fig. 2.

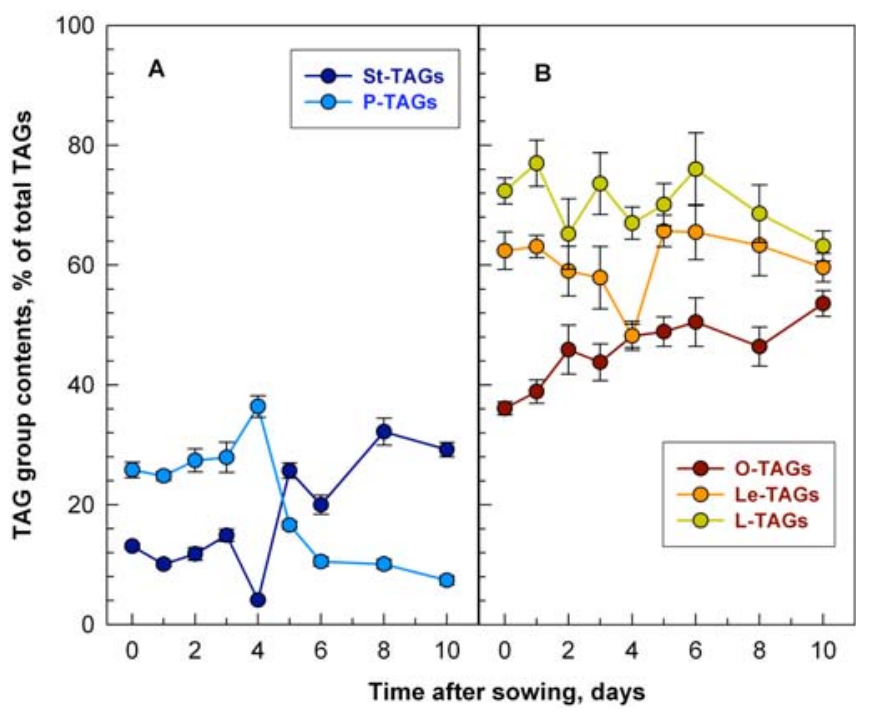

Fig. (6). Developmental changes in the relative content of separate TAG groups of sea buckthorn seedling cotyledons. A: S-TAGs; B: U-TAGs. See also Fig. 2.

All the indices cited above noticeably differed in their pattern from the respective results published previously. Thus, in most plant species investigated so far, the FA composition of TAGs generally remained constant $[10,12,13$, 24, 26, 28, 32-37]. Moreover, in contrast to our results, there were an increase in the P level $[15,19,34]$, a decrease in St $[17,19]$ and $O$ concentrations [15, 17, 18, 27, 37-39], as well as shifts in L and Le contents [11, 15, 17-19, 38-41]. Finally, the changes found in our studies, viz. a decrease in the $\mathrm{P}$ 
level [17, 41] and a rise in $O$ concentration $[19,25,40]$, were rarely observed by other workers, while a rise in St content was noticed in no case up to now. Thus, the pattern of changes in the quantitative FA composition of TAGs of higher plant seedlings turned out to be a contradictory one. The contradictions found here can be considered to be related to differences in the germination conditions used, germination stage, plant genotype, analytical methods, etc. [26].

As stated above, the changes in TAG PTC of germinating seeds were not investigated previously. The respective evidence for sea buckthorn (Fig. 4) corresponded to the pattern of dynamics of FA PTC in Fig. (3). In both cases, $\mathrm{S}$ and U values (Fig. 3), on the one hand, and $\mathrm{UUU}, \mathrm{SU}_{2}$, and $\mathrm{S}_{2} \mathrm{U}$ values, on the other hand (Fig. 4), generally varied in parallel to each other. Such TAG PTC dynamics pointed to a lack of selectivity in the utilization of separate TAG types in sea buckthorn cotyledons, including the types, which contained $\mathrm{S}$-FAs, such as $\mathrm{S}_{2} \mathrm{U}$ and $\mathrm{SU}_{2}$. Meanwhile, in the contents of individual $\mathrm{S}$ species, such as $\mathrm{P}$ and $\mathrm{St}$, in the total TAGs, there were essential shifts, and therefore we determined possible changes in the TAG PSC during germination. It was found that this process was indeed accompanied by an increase in St-TAG level and a decrease in P-TAG relative content (Fig. 6A). Besides, a noticeable increase in O-TAG concentration and constancy in L-TAG and Le-TAG contents were observed (Fig. 6B). Thus, throughout the entire period of cotyledon growth, the rate of L-TAG and Le-TAG breakdown changed insignificantly, P-TAGs rapidly degraded after the 4th day of germination, while the intensity of St-TAG and, to a lesser degree, O-TAG consumption markedly decreased during almost the entire germination period. As a whole, the seed TAG composition changed during germination to a lesser extent than at maturation [7].

A prevalent breakdown of P-TAGs observed here was also demonstrated during soybean germination, where they were consumed several fold more rapidly than the triunsaturated TAGs [13]. At the same time, unlike the respective situation in sea buckthorn, the monounsaturated TAGs were considerably below the di- and triunsaturated TAGs in the rate of their metabolization in canola seedlings [18], and OTAGs exceeded the L-TAGs in the intensity of their degradation during the germination of sunflower [20] and dioscorea [21] seeds. Finally, TAG composition did not change at all during the germination of seeds of nut pine [9], hazel [16], and Andropogon gayanus [42]; these TAGs were mainly composed of $\mathrm{P}_{2} \mathrm{O}, \mathrm{P}_{2} \mathrm{~L}, \mathrm{PO}_{2}, \mathrm{POL}, \mathrm{O}_{3}, \mathrm{PL}_{2}, \mathrm{O}_{2} \mathrm{~L}$, $\mathrm{L}_{2} \mathrm{O}$, and $\mathrm{L}_{3}$.

\section{CONCLUSION}

Thus, lipid metabolism in the actively growing sea buckthorn seedlings was first of all characterized by a very rapid TAG consumption. During this process, various TAG types were broken down at nearly the same relative rate, while separate TAG groups, which included particular individual FA species, could considerably differ from one another in the intensity of their degradation. Further studies of quantitative dynamics of individual TAG species of various FA compositions during TAG metabolization will promote the elucidation of the function of each of these species in this process.

\section{ACKNOWLEDGEMENTS}

This work was supported in part by the Russian Foundation for Basic Research, project no. 07-04-00083.

$\begin{array}{lll}\text { ABBREVIATIONS } \\ \text { ACP } & =\text { Acyl-carrier protein } \\ \text { ACL } & = & \text { Acylcontaining lipid } \\ \text { L } & = & \text { Linoleic acid } \\ \text { Le } & = & \text { Linolenic acid } \\ \mathrm{O} & = & \text { Oleic acid } \\ \mathrm{P} & = & \text { Palmitic acid } \\ \text { St } & = & \text { Stearic acid } \\ \text { FA } & = & \text { Fatty acid } \\ \text { PSC } & = & \text { Positional-species composition } \\ \text { PTC } & = & \text { Positional-type composition } \\ \text { S } & = & \text { Total saturated FAs } \\ \text { TAG } & = & \text { Triacylglycerol } \\ \text { U } & = & \text { Total unsaturated FAs. }\end{array}$

\section{REFERENCES}

[1] Berezhnaya GA, Ozerinina OV, Yeliseev IP, Tsydendambaev VD, Vereshchagin AG. Developmental changes in the absolute content and fatty acid composition of acyl lipids of sea buckthorn fruits. Plant Physiol Biochem 1993; 31: 323-32.

[2] Ozerinina OV, Berezhnaya GA, Yeliseev IP, Vereshchagin AG. Triacylglycerol composition and structure in sea buckthorn fruit mesocarp. Prikl Biokhim Mikrobiol 1988; 24: 422-9.

[3] Vereshchagin AG, Ozerinina OV, Tsydendambaev VD. Occurrence of two different systems of triacylglycerol formation in sea buckthorn fruit mesocarp. J Plant Physiol 1998; 153: 208-13.

[4] Vereshchagin AG, Tsydendambaev VD. Developmental changes in the triacylglycerol composition of sea buckthorn fruit mesocarp. J Plant Physiol 1999; 155: 453-61.

[5] Vereshchagin AG, Pchelkin VP, Kuznetsova EI, Tsydendambaev VD. Distribution of unusual fatty acids in the triacylglycerols of sea buckthorn mesocarp oil. In: Benning Ch, Ohlrogge J, Eds. Current advances in the biochemistry and cell biology of plant lipids. Aardwark Publ Co., Salt Lake City: USA 2007; pp. 224-7.

[6] Ozerinina OV, Berezhnaya GA, Yeliseev IP, Vereshchagin AG. Triacylglycerol composition and structure in Hippophae rhamnoides seeds. Khimiya Prirodnykh Soedinenii 1987; 1: 52-7.

[7] Tsydendambaev VD, Vereshchagin AG. Changes in triacylglycerol composition during ripening of sea buckthorn (Hippophae rhamnoides L.) seeds. J Agric Food Chem 2003; 51: 1278-83.

[8] Berezhnaya GA, Yeliseev IP, Tsydendambaev VD, Vereshchagin AG. Determination of fatty acid composition and quantitative content of lipids in sea buckthorn fruits. Prikl Biokhim Mikrobiol 1988; 24: 568-73.

[9] Hammer MF, Murphy JB. Lipase activity and in vivo triacylglycerol utilization during Pinus edulis seed germination. Plant Physiol Biochem 1994; 32: 861-7.

[10] Senanayake SPJ, Shahidi F. Lipid components of borage (Borago officinalis L.) seeds and their changes during germination. J Am Oil Chem Soc 2000; 77: 55-61.

[11] Yaniv Z, Shabelsky E, Schafferman D, Granot I, Kipnis T. Oil and fatty acid changes in Sinapis and Crambe seeds during germination and early development. Ind Crops Products 1998; 9: 1-8.

[12] Wanasundara PKJPD, Wanasundara UN, Shahidi F. Changes in flax (Linum usitatissmum L.) seed lipids during germination. J Am Oil Chem Soc 1999; 76: 41-8.

[13] Yoshida H. Molecular species and fatty acid distribution of triacylglycerols from germinating soybean cotyledons. Lipids 1984; 19: 936-41. 
[14] Bhatia IS, Singh IP, Sukhija PS. Lipids in berseem seed (Trifolium alexandrinum) during germination as affected by gibberellic acid and maleic hydrazide. Physiol Plant 1974; 30: 288-90.

[15] El-Sebaiy LA, El-Mahdy AR. Lipid changes during germination of fenugreek seeds (Trigonella foenum-graecum). Food Chem 1983; 10: 309-19.

[16] Shewry PR, Pinfield NJ, Stobart AK. The glycerides and acyl fatty acids of germinating hazel seeds. Phytochemistry $1972 ; 11 ; 2149$ 54.

[17] Joshi AC, Chopra BK, Doctor VM. Distribution of fatty acids during germination of soybean seeds. J Am Oil Chem Soc 1973; 50: $282-3$.

[18] Thompson GA, Li CY. Altered fatty acid composition of membrane lipids in seeds and seedling tissues of high-saturate canolas. In: Williams JP, Khan MU, Lem NW, Eds. Physiology, biochemistry and molecular biology of plant lipids. Kluwer Dordrecht: Holland: 1997; pp. 313-5.

[19] Belver A, Daza LM, Donaire JP. Action of boron in vivo on fatty acid content and lipoxygenase activity in cotyledons during germination of the sunflower seeds. In: Wintermans JFGM, Kuiper PJC, Eds. Biochemistry and metabolism of plant lipids. Elsevier Biomedical Press, Amsterdam: Holland 1982; pp. 283-6.

[20] Fernandez-Moya V, Martinez-Force E, Garces R. Metabolism of triacylglycerol species during seed germination in fatty acid sunflower (Helianthus annuus) mutants. J Agric Food Chem 2000; 48: 770-4.

[21] Okagami N, Terui K. Differences in the rates of metabolism of various triacylglycerols during seed germination and the subsequent growth of seedlings of Dioscorea toroco, a perennial herb. Plant Cell Physiol 1996; 37: 273-7.

[22] Joshi AC, Doctor VM. Distribution of fatty acids during germination of cottonseeds. Lipids 1975; 10: 191-3.

[23] Lehle FR, Staniforth DW, Stewart CR. Lipid mobilization in dormant and nondormant caryopses of yellow foxtail (Setaria lutescens). Weed Sci 1983; 31: 28-36.

[24] Koiwai A, Matsuzaki T. Changes in the glycerolipid content and fatty acid composition during tobacco seed germination. Phytochem 1990; 29: 73-6.

[25] Izzo R, Navari-Izzo F, Panicucci M. Changes in fatty acid composition in Zea mays L. during germination. Agrochimica 1983; 27: 252-8.

[26] Meletiou-Christou MS, Diamantoglu S, Mitrakis K. Analysis of lipids of Citrullus lanatus (cv. Sugar Baby) during seed germination and seedling growth. J Exp Bot 1990; 41: 1455-60.
[27] Miled-Daoud DB, Cherif A. Effet du $\mathrm{NaCl}$ sur l'utilisation des lipides et les activites enzymatiques glyoxysomales au cours de la germination de deux especes de Medicago. Can J Bot 1992; 70: 876-83.

[28] Marriott KM, Northcote DH. The breakdown of lipid reserves in the endosperm of germinating castor beans. Biochem J 1975; 148: $139-44$.

[29] Liu KS, Brown EA. Fatty acid compositions in newly differentiated tissues of soybean seedlings. J Agric Food Chem 1996; 44: 1395-8.

[30] Groeneveld HW, Elings JC, Blanco M, Gramwell D. Mobilization of reserves and synthesis of sterols and triterpenes in seedlings of Euphorbia species. Ann Bot 1988; 62: 303-11.

[31] Miled-Daoud DB, Cherif A. Salt effect on lipid metabolism of rape seeds during germination. In: Kader JC, Mazliak P, Eds. Plant lipid metabolism. Kluwer, Dordrecht: Holland 1995; pp. 423-5.

[32] Carballeira MJ, Martin L, Nicolas G, Villalobos N. Analysis of lipids and fatty acids during germination of Brassica campestris cv. Eculenta seeds. Plant Sci 1987; 49: 181-8.

[33] Nartey F, Moller BL. Fatty acid profiles in germinating Manihot esculenta. Phytochemistry 1973; 12: 2909-11.

[34] Cantisan S, Martinez-Force E, Alvarez-Ortega R, Garces R. Lipid characterization in vegetative tissues of high saturated fatty acid sunflower mutants. J Agric Food Chem 1999; 47: 78-82.

[35] Pandey SS, Subrahmanyam VVR. Lipid changes in maturing and germinating cottonseeds. Phytochemistry 1988; 27: 3405-09.

[36] Huang LS, Grunwald C. Lipid and fatty acid changes during germination of alfalfa seeds. Phytochemistry 1990; 29: 1441-5.

[37] Holmer G, Ory RL, Hoy CE. Changes in lipid composition of germinating barley embryo. Lipids 1973; 8: 277-83.

[38] Kumar V, Rani A, Chauhan GS. Influence of germination temperature on oil content and fatty acid composition of soy sprouts. J Food Sci Technol 2006; 43: 325-6.

[39] Rabiei Z, Tahmasebi-Enferadi S, Giovanardi R, Vannozzi GP. Linolenic acid synthesis pathway: high and low oleic acid sunflower inbred lines after seeding. In: Benning Ch, Ohlrogge J, Eds. Current advances in the biochemistry and cell biology of plant lipids. Aardwark Publ Co., Salt Lake City: USA 2007; pp. 199-202.

[40] Dhaliwal YS, Aggarwal RAK. Composition of fat in soybean as affected by duration of germination and drying temperature. J Food Sci Technol 1999; 36: 266-7.

[41] de la Haba P, Munoz J, Jimenez F. Fatty acid evolution in germinating soybean seeds pretreated with boron and GA3. Agrochimica 1987; 31: 414-24.

[42] Williams PM, Bowden BN. Triglyceride metabolism in germinating Andropogon gayannys seeds. Phytochemistry 1973; 12: 2821-7.

(C) Pchelkin et al.; Licensee Bentham Open.

This is an open access article licensed under the terms of the Creative Commons Attribution Non-Commercial License (http://creativecommons.org/licenses/by$\mathrm{nc} / 3.0 /$ ) which permits unrestricted, non-commercial use, distribution and reproduction in any medium, provided the work is properly cited. 